\title{
Labour room birth records of Kwong Wah Hospital since 1935
}

\author{
WC Leung ${ }^{1}$ *, MD, FHKAM (Obstetrics and Gynaecology), SM Tai ${ }^{1}$, BHSc, MSSc, Alice Sham ${ }^{1}$, BN, MSSc, Winnie Yip², BA, MA, \\ Stella See ${ }^{2}$, BA
}

This article was published on 20 Oct 2021 at www.hkmj.org.

\author{
${ }^{1}$ Department of Obstetrics and Gynaecology, Kwong Wah Hospital, Hong Kong \\ ${ }^{2}$ Records and Heritage Office, Tung Wah Group of Hospitals, Hong Kong
}

*Corresponding author: leungwc@ha.org.hk
This year marks the 110th anniversary of the foundation of Kwong Wah Hospital. As the first hospital on the Kowloon Peninsula, Kwong Wah Hospital was closely connected with the Tung Wah Hospital established under the Chinese Hospital Incorporation Ordinance ${ }^{1}$ promulgated in 1870 as the first hospital on Hong Kong Island providing free Chinese medicine care to the indigent Chinese.

On 24 August 1911, the Government promulgated the Tung Wah Hospital Extension Ordinance $^{2}$ whereby Kwong Wah Hospital was established as a Kowloon branch of the Tung Wah Hospital. It was on the basis of this Ordinance that the amalgamation of three Tung Wah Hospitals came into being in 1931 as the "Tung Wah Group of Hospitals", after the establishment of the Tung Wah Eastern Hospital in So Kon Po on Hong Kong Island in 1929.

Kwong Wah Hospital was officially opened on 9 October 1911. Unlike Tung Wah Hospital, which initially provided only traditional Chinese medicine care, Kwong Wah Hospital provided both Chinese and Western medicine care from the very beginning.

In 2011, the Administrative Services Department of Kwong Wah Hospital approached the Records and Heritage Office of the Tung Wah Group of Hospitals to invite advisers and members of the Records and Heritage Committee to give advice on preservation of some very old records in their Records Office. With participation from academics and the Director of the Conservation Office of the Leisure and Cultural Services Department the archives were accorded high importance for safeguarding the medical heritage of Hong Kong. Thus, it was decided that Kwong Wah Hospital would avail the earliest available hospital register of 1917 for Tung Wah Group of Hospitals and the Leisure and Cultural Services Department to launch an experimental conservation project to restore the first registry. The project was successfully completed in early 2012. Tung Wah allocated funds to continue to conserve the remaining 157 items of Chinesestyle hospital registers.

In 2016, Kwong Wah Hospital sought the agreement of the Hospital Authority to transfer
1249 items of records of the hospital from 1917 to 1991 (before the hospital joined the Hospital Authority) to the Records and Heritage Office for permanent custody. In addition to the large collection of hospital registers, in which the patient's name, hometown, address, age, symptoms, and other information were recorded, there were 377 items of birth records from 1935 to 1991, in which the mother's name, age, address, number of births, husband's profession, and other information were recorded. The condition of some of these archives was extremely poor (Fig 1). The Records and Heritage Office arranged for conserving (Fig 2) and digitising the records. The full set of digital birth records provided to Kwong Wah Hospital enable the answering of hundreds of enquiries from the public each year regarding birth information. All 1249 items in the archives are now kept in the TWGHs Maisy Ho Archives and Relics Centre as part of the Group archives.

In the present Commentary, we look at the labour room birth record archives from 1935 and compare these historical data with similar data from modern day obstetrics.

The labour room birth records started in 1935 most likely to facilitate the amendment of the Births and Deaths Registration Ordinance ${ }^{3}$ in 1934 which encouraged the registration of all births and the issue of birth certificates at no cost to the patient, as well as to facilitate vaccination.

From the data available, we selected four periods to compare the labour room birth records: the beginning of labour room birth records (19361938); the Japanese occupation of Hong Kong during the Second World War (1941-1944); the post-war period (1948-1950); and the modern obstetrics era (2014-2016) [Table]. ${ }^{4}$

Compared with the historical data, in modern obstetrics there were significant decreases in maternal mortality and neonatal death, which are obviously related to healthcare improvements in modern obstetrics and neonatal intensive care unit support. The same applied to the significant reduction of eclampsia in modern obstetrics. In contrast, increasing use of interventions such as 
instrumental deliveries and Caesarean sections in modern obstetrics has resulted in a significant reduction in normal vaginal deliveries, nowadays known as medicalisation of childbirth. This includes vaginal breech deliveries after the Term Breech Trail by Hannah et $\mathrm{al}^{5}$ showed the higher risk of vaginal breech delivery to the newborns. The first Caesarean section in Kwong Wah Hospital was performed on 24 April 1937, according to labour room birth records.

Compared with the historical data, in modern obstetrics there have been significant increases in postpartum haemorrhage and retained placenta (might be the result of different definitions and accuracy of documentation), as well as twin pregnancies (definitely related to the invention of assisted reproduction technology in modern era). The significant increase in placenta praevia in modern obstetrics did worth special mentioning. A major contributing factor is the increasing Caesarean section rate. Note that placenta praevia together with previous Caesarean section could result in

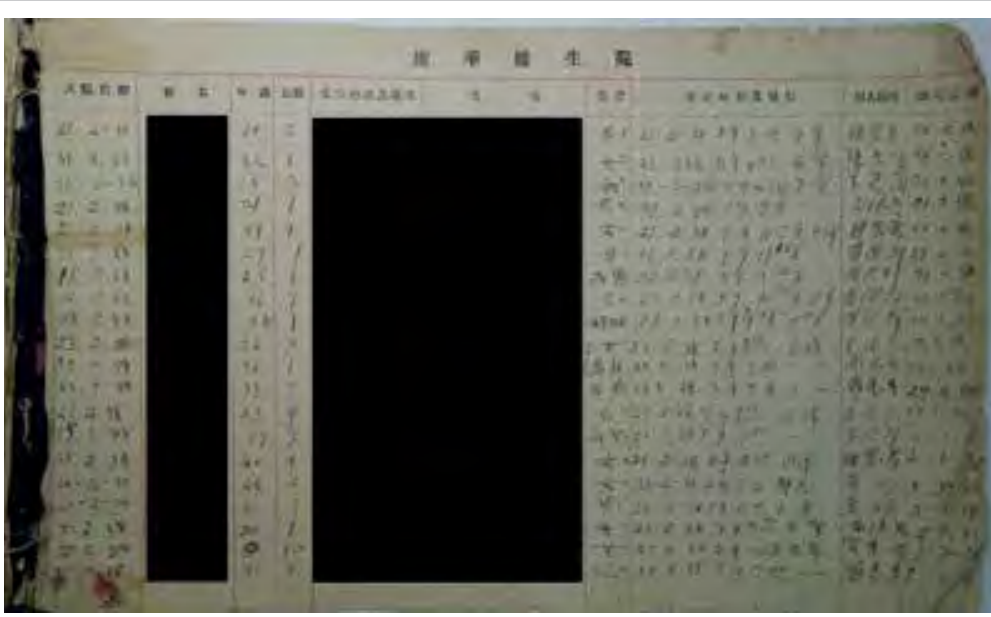

FIG I. Photograph of a typical page from the labour room birth records of Kwong Wah Hospital in 1938. Information recorded includes (from left to right) the date of admission, the patient's name, maternal age, parity, husband's name and occupation, address, baby gender, delivery date and time and condition at birth, midwife or obstetrician conducting the delivery, and date of discharge

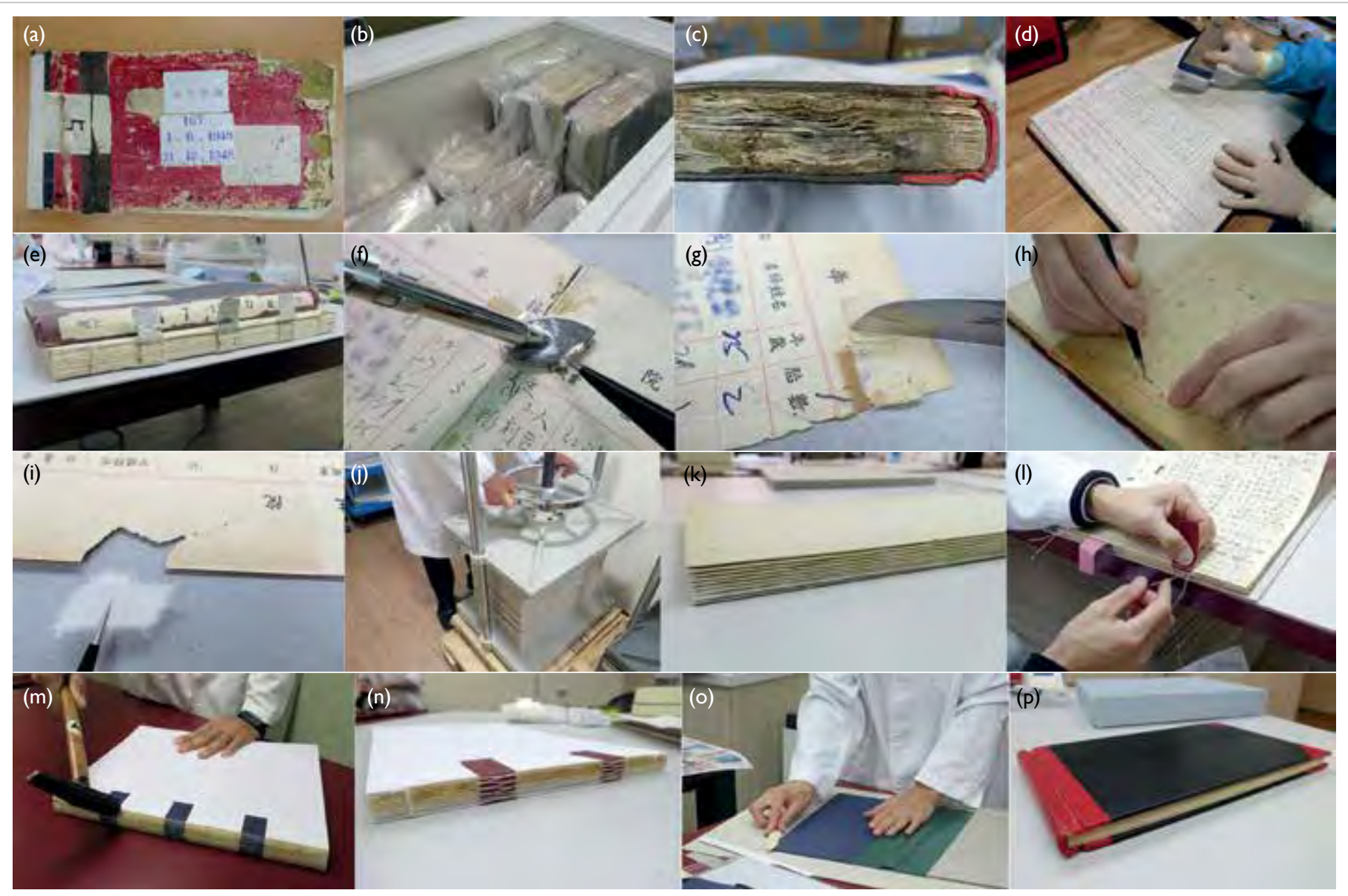

FIG 2. Conservation of the labour room birth records of Kwong Wah Hospital. (a) The labour room birth record book of Kwong Wah Hospital before treatment. The multi-stage treatment consists of (b) freezing, (c) cleaning to remove mould residue, (d) cleaning the surface, (e) unbinding, (f) removing any tape, (g) removing adhesive residue, (h) removing nails and staples, (i) repairing the paper, (j) pressing, (k) reassembling the textblock, (l) stitching, $(\mathrm{m})$ rounding, $(\mathrm{n})$ gluing, and $(\mathrm{o})$ making the case. $(\mathrm{p})$ The finished rebound labour room birth record 
TABLE. Labour room birth records of Kwong Wah Hospital from the beginning of the labour room records (I936-1938), the Japanese occupation of Hong Kong (194I-1944), and the post-war period (1948-1950) compared with the modern obstetrics era (2014-2016)*

\begin{tabular}{|c|c|c|c|c|c|}
\hline Years & 1936-1938 & 1941-1944 & $1948-1950$ & 2014-2016 & P value $^{\dagger}$ \\
\hline Total maternity patients, No. & 11651 (3884/yr) & 3037 (759/yr) & 20681 (6894/yr) & 15491 (5164/yr) & \\
\hline Normal spontaneous deliveries & $10859(93.2 \%)$ & $2801(92.2 \%)$ & $19386(93.7 \%)$ & 11405 (73.6\%) & $<0.00001$ \\
\hline $\begin{array}{l}\text { Instrumental deliveries (forceps / } \\
\text { vacuum extraction) }\end{array}$ & $105(0.9 \%)$ & $50(1.6 \%)$ & $253(1.2 \%)$ & $611(3.9 \%)$ & $<0.00001$ \\
\hline Caesarean section & $5(0.04 \%)$ & $8(0.3 \%)$ & $28(0.14 \%)$ & $3475(22.4 \%)$ & $<0.00001$ \\
\hline Vaginal breech delivery & $242(2.1 \%)$ & $112(3.7 \%)$ & $475^{\ddagger}(2.3 \%)$ & $23(0.15 \%)$ & $<0.00001$ \\
\hline Postpartum haemorrhage & $29(0.25 \%)$ & $12^{\ddagger}(0.4 \%)$ & $4^{\ddagger}(0.02 \%)$ & $972(6.3 \%)$ & $<0.00001$ \\
\hline Retained placenta & $41(0.35 \%)$ & $15^{\ddagger}(0.49 \%)$ & $67(0.32 \%)$ & $81(0.52 \%)$ & 0.017 \\
\hline Twin pregnancy & $75^{\ddagger}(0.64 \%)$ & $28(0.92 \%)$ & $151(0.73 \%)$ & $278(1.8 \%)$ & $<0.00001$ \\
\hline Placenta praevia & $80(0.69 \%)$ & $34(1.1 \%)$ & $88(0.43 \%)$ & $242(1.6 \%)$ & $<0.00001$ \\
\hline Eclampsia & $57^{\ddagger}(0.49 \%)$ & $39 \ddagger(1.3 \%)$ & $50 \ddagger(0.24 \%)$ & $4(0.03 \%)$ & $<0.00001$ \\
\hline Maternal mortality & $49(0.42 \%)$ & $37(1.2 \%)$ & $46(0.22 \%)$ & 0 & $\begin{array}{l}\text { Chi squared test } \\
\text { not applicable }\end{array}$ \\
\hline Stillbirth & $59 \ddagger(0.5 \%)$ & $196(6.5 \%)$ & $\mathrm{N} / \mathrm{A}$ & $40(0.26 \%)$ & $<0.00001$ \\
\hline Neonatal death & $523^{\ddagger}(4.5 \%)$ & $101^{\ddagger}(3.3 \%)$ & $\mathrm{N} / \mathrm{A}$ & $12(0.08 \%)$ & $<0.00001$ \\
\hline
\end{tabular}

Abbreviation: N/A = not available

* Data are presented as No. (\%) except where otherwise indicated

$P$ values calculated using Chi squared test for comparing the proportions in different time periods

‡ Data estimated pro rata, when not available in every year during the study periods

placenta accreta, which has been described to be a 20th century iatrogenic uterine disease. ${ }^{6}$

Kwong Wah Hospital continued offering free clinical service during wartime, but there were far fewer pregnancies or maternities than before or after the war. The expected difficulty for pregnant women to access to hospital could explain the significant increases in maternal mortality and stillbirths during wartime.

\section{Author contributions}

All authors contributed to the concept or design of the study, acquisition of data, analysis or interpretation of data, drafting of the manuscript, and critical revision of the manuscript for important intellectual content. All authors had full access to the data, contributed to the study, approved the final version for publication, and take responsibility for its accuracy and integrity.

\section{Conflicts of interest}

All authors have disclosed no conflicts of interest.

\section{Acknowledgement}

Special thanks to Records and Heritage Office and Maisy Ho Archives and Relics Centre, Tung Wah Group of Hospitals for providing the history of Kwong Wah Hospital and conservation of the labour room birth records from 1935 .

\section{Declaration}

Some of the findings from this study were presented on 7 September 2019 as part of a series of talks titled "Charity and Healthcare: Tung Wah Archives and Hong Kong's Early Healthcare Development" (https://www.tungwah.org.hk/ en/heritage-news/subject-talks-and-roving-exhibitions-incharity-and-healthcare-tung-wah-archives-and-hong-kongsearly-healthcare-development/).

\section{Funding/support}

This study received no specific grant from any funding agency in the public, commercial, or not-for-profit sectors.

\section{References}

1. The Chinese Hospital Incorporation Ordinance. 1870.

2. The Tung Wah Hospital Extension Ordinance. 1911.

3. The Births and Deaths Registration Ordinance. 1934.

4. Annual Obstetrics Report 2014 to 2016. Department of Obstetrics \& Gynaecology, Kwong Wah Hospital, Hong Kong SAR Government.

5. Hannah ME, Hannah WJ, Hewson SA, Hodnett ED, Saigal S, Willan AR. Planned caesarean section versus planned vaginal birth for breech presentation at term: a randomised multicentre trial. Term Breech Trial Collaborative Group. Lancet 2000;356:1375-83.

6. Jauniaux E, Jurkovic D. Placenta accreta: pathogenesis of a 20th century iatrogenic uterine disease. Placenta 2012;33:244-51. 